Fantle-Lepczyk, J. E., L. Berry, C. Lepczyk, D. C. Duffy and S. Conant. 2018. Key demographic factors for recovery of the endangered Nightingale Reed-Warbler (Acrocephalus hiwae) via population viability analysis. Avian Conservation and Ecology 13(2):13. https://doi. org/10.5751/ACE-01289-130213

Copyright (C) 2018 by the author(s). Published here under license by the Resilience Alliance.

Research Paper

\title{
Key demographic factors for recovery of the endangered Nightingale Reed-Warbler (Acrocephalus hiwae) via population viability analysis
}

Jean E. Fantle-Lepczyk ${ }^{1}$, Lainie Berry ${ }^{2}$, Christopher Lepczyk ${ }^{3}$, David C. Duffy ${ }^{4}$ and Sheila Conant ${ }^{1}$

${ }^{1}$ Department of Biology, University of Hawai'i at Mānoa, Honolulu, Hawai'i, USA, ${ }^{2}$ Hawai'i Division of Forestry and Wildlife, Honolulu, Hawai'i, USA, ${ }^{3}$ School of Forestry and Wildlife Sciences, Auburn University, Auburn, Alabama, USA, ${ }^{4}$ Pacific Cooperative Studies Unit, Department of Botany, University of Hawai'i at Mānoa, Honolulu, Hawai'i, USA

\begin{abstract}
The Nightingale Reed-Warbler (Acrocephalus hiwae), a critically endangered songbird, is the last remaining of four reed-warbler species that once inhabited the Mariana Islands. The most recent population estimate for the species is $2915-3742$ individuals distributed over the islands of Saipan $(n=2742,95 \% \mathrm{CI}=1686-3956)$ and Alamagan $(\mathrm{n}=946,95 \% \mathrm{CI}=173-1000)$, which represents a significant decline for the species on Saipan. Though data on life history parameters such as survival rates are not widely available, other parameters such as clutch size and nest success have been studied. Given the extirpation of three of the four reed-warbler species from the Mariana Islands, the recent significant decline of the larger Saipan population, and the increasing threats faced by the species, it is critical to determine what additional life history information is needed to aid management decisions. Using Vortex, we developed stochastic population models to represent current reed-warbler population dynamics and used sensitivity analysis to identify the life history parameters to which the model was most sensitive. Baseline models without inbreeding indicated declines of the Nightingale Reed-Warbler populations on Saipan and Alamagan, as well as of the overall population. The inclusion of inbreeding further increases the modeled rate of population decline. Parameters such as initial population size, carrying capacity, and male survival have relatively little influence on reed-warbler population models, while female and juvenile survival and, to a lesser degree, fecundity measures, exhibit strong influences on the species' population dynamics. We recommend effort be placed on collecting updated survival data for all life stages, but particularly for females and juveniles. Given model predictions of vulnerability to extinction, we recommend management actions that may increase survival rates of juveniles and females.
\end{abstract}

\section{Facteurs démographiques clés pour le rétablissement de la Rousserolle de Saipan (Acrocephalus hiwae), en voie de disparition critique, au moyen d'analyses de viabilité des populations}

RÉSUMÉ. La Rousserolle de Saipan (Acrocephalus hiwae), un passereau en voie de disparition critique, est la dernière des quatre espèces de rousseroles qui se reproduisaient autrefois sur les Mariannes. L'estimation la plus récente de la population de cette rousserolle est de 2 915-3 742 individus répartis sur les îles de Saipan (n=2 742, IC $95 \%=1686-3$ 956) et Alamagan (n = 946, IC $95 \%=173-1000$ ), ce qui représente une baisse importante de l'espèce sur Saipan. Bien que certaines composantes biodémographiques comme le taux de survie ne soient pas disponibles à grande échelle, d'autres paramètres tels que la taille de la ponte et le succès de nidification ont été bien étudiés. Étant donné la disparition de trois des quatre espèces de rousseroles des Mariannes, du récent déclin prononcé de la plus importante population sur Saipan et des menaces grandissantes auxquelles fait face l'espèce, il est primordial de déterminer quels paramètres de la biodémographie sont nécessaires pour orienter les décisions de gestion. Au moyen de Vortex, nous avons développé des modèles de population stochastiques représentant la dynamique actuelle de population des rousseroles et avons utilisé des analyses de sensibilité pour identifier quels paramètres démographiques influaient le plus sur les modèles. Les modèles de base sans consanguinité ont pointé vers une baisse des populations de Rousserolle de Saipan sur Saipan et Alamagan, de même que pour l'ensemble de la population. L'inclusion de la consanguinité dans le modèle a mené à un taux de diminution des populations encore plus élevé. Les paramètres tels que la taille initiale de la population, la capacité de support et la survie des mâles ont relativement peu d'effet sur les modèles de population des rousserolles, alors que la survie des femelles et des jeunes, et à un moindre degré, les mesures de la fécondité, ont un effet important sur la dynamique de population de l'espèce. Nous recommandons d'orienter les efforts sur la collecte de données permettant une mise à jour des taux de survie à tous les stades de vie, mais plus particulièrement pour les femelles et les jeunes. Considérant les prédictions des modèles révélant une vulnérabilité à la disparition, nous recommandons d'appliquer des mesures de gestion qui puissent hausser le taux de survie des femelles et des jeunes.

Key Words: Acrocephalus hiwae; ga'ga' karisu; Mariana Islands avifauna; PVA; Vortex

Address of Correspondent: Jean E. Fantle-Lepczyk, 1201 Hickory Lane, Auburn, AL, United States, 36830, fantle@hawaii.edu 


\section{INTRODUCTION}

The Nightingale Reed-Warbler (Acrocephalus hiwae), known in Chamorro as ga'ga' karisu (bird of the reeds), is an IUCNcritically endangered insectivorous songbird of Saipan and Alamagan, Mariana Islands (Saitoh et al. 2012, BirdLife International 2016), and is listed as Endangered under the U.S. Endangered Species Act (USFWS 1970). The Mariana Islands are an approximately $840 \mathrm{~km}$-long arc comprising 15 main islands, running approximately north-south from Uracas at latitude $20.5^{\circ}$ $\mathrm{N}$ to Guam at latitude $13.5^{\circ} \mathrm{N}$, in the Western Pacific Ocean. The largest island is Guam, and only four (Guam, Rota, Tinian, and Saipan) are permanently occupied. Of the four reed-warbler species that formerly inhabited this island chain, only the Nightingale Reed-Warbler remains. The Nightingale ReedWarbler's sister species, A. nijoi, A. luscinius, and A. yamashinae, have been extirpated from Aguiguan, Guam, and Pagan, respectively (Saitoh et al. 2012). Though the Nightingale ReedWarbler has persisted, the most recent population estimates indicate an estimated total of only about 3688 individuals distributed over the islands of Saipan in 2007 ( $n=2742,95 \%$ CI = 1686-3956; Camp et al. 2009) and Alamagan in $2010(\mathrm{n}=946$, 95\% CI = 173-1000; Marshall et al. 2011). The population on Saipan appears to have been nearly halved from an estimated 4867 individuals in 1982 (Engbring et al. 1986), although the numbers appear more stable on Alamagan, with a previous estimate of 1125 individuals (95\% CI $=504-1539$ ) in 2000 (Cruzet al. 2000a).

The decline of the Nightingale Reed-Warbler, and extinction of the other three reed-warbler species in the Mariana Islands, has been driven by several factors. One of the most detrimental has been habitat loss. Reed-warblers of the Marianas occur in a variety of habitats, including thickets, forest edges and openings, native reed-mar, mangrove wetland, as well as upland introduced Leucaena leucocephala forest and mosaics of elephant grass (Pennisetum purpureum) and tangan-tangan (Ricinus communis; Craig 1992, Reichel et al. 1992, USFWS 1998, Mosher and Fancy 2002). However, much of Saipan's wetlands and forests have been converted to agriculture, residential development, and touristrelated facilities over the last several decades, reducing suitable habitat for the Nightingale Reed-Warbler (USFWS 1998). Exacerbating this loss is the spread of non-native vines, especially ivy gourd (Coccinia grandis; Liske-Clark 2015), which has invaded $\sim 90 \%$ of Saipan's forests since its introduction in the mid-1990s (Deleon Guerrero 2015). This species smothers the forest canopy until it collapses because of tree death (Global Invasive Species Database 2017), thereby destroying reed-warbler nesting habitat.

Degradation of habitat by feral ungulates, e.g., goats, has also contributed to the extirpation of $A$. nijoi on Aguiguan and $A$. yamashinae on Pagan (Cruz et al. 2000b). Severe habitat damage from feral goats, pigs, and cows may be causing Nightingale ReedWarbler population decline on Alamagan, while continued grazing on Aguiguan may limit opportunities for recolonization or reintroduction (Cruz et al. 2000a, b). Introduced predators including cats (Felis catus), rats (Rattus spp.), monitor lizards (Varanus indicus), and brown treesnakes (Boiga irregularis) also play a significant role in reed-warbler declines throughout the Marianas (USFWS 1998). Predation, mostly by non-native species, was responsible for $75 \%$ of nest failures (rats [71\%], cats [5\%] and unknown predators [24\%]; Mosher 2006). Monitor lizards and the native Mariana kingfisher (Todiramphus albicilla) may also depredate reed-warbler nests. Of particular concern is the brown treesnake, which greatly reduced or extirpated most native birds, including the reed-warbler, within 35-40 years after its accidental introduction on Guam (Reichel et al. 1992). The brown treesnake was the primary cause of extirpation of $A$. luscinius on Guam (Rodda and Savidge 2007), and the potential for invasion by the brown treesnake on Saipan (and, though less likely, Alamagan) places the Nightingale Reed-Warbler population at risk.

To address these threats, current Nightingale Reed-Warbler management protocols include protecting and managing extant populations and core habitat (USFWS 1998). Regular population surveys have been run to assess population trends (Engbring et al. 1986, Cruz et al. 2000a, b, Esselstyn et al. 2003, Camp et al. 2009, Marshall et al. 2011, Amidon et al. 2014). Another integral aspect of the species' recovery is continued protection against brown treesnake incursions through monitoring and removal of brown treesnakes.

Population viability analysis (PVA) is a useful tool to assess management options to reduce the risk of extinction (Ellner and Fieberg 2003). PVA incorporates demographic and environmental variables to forecast population persistence and extinction risk, thereby testing the relative importance of model parameters via sensitivity analysis, evaluating management strategies, and identifying priorities for maximizing effective species recovery (Beissinger and Westphal 1998, Brook et al. 2000, Cross and Bessinger 2001, Reed et al. 2002).

Although data on some life history parameters such as survival rates of the Nightingale Reed-Warbler are not widely available, other parameters such as clutch size and nest success have been well-studied (Mosher and Fancy 2002, Mosher 2006). Considering the significant decline in the larger Saipan population in recent years (Camp et al. 2009) and the increasing threats faced by the species, it is critical to determine what additional life history information is needed to aid management decisions, as well as what management actions can assist the Saipan reed-warbler population. To address these needs, our overarching goal was to evaluate possible population trajectories of the Nightingale Reed-Warbler and identify key life history attributes important to understand species population dynamics. Based upon this goal our objectives were the following: (1) to model Nightingale Reed-Warbler population dynamics on both Saipan and Alamagan for the next 100 years; and, (2) to conduct sensitivity analysis on life history attributes to determine which, if any, parameters are most influential in model outcomes.

\section{METHODS}

\section{PVA software}

We conducted our PVAs using Vortex 10 (Lacy and Pollack 2014), which simulates stochastic demographic and environmental processes. Vortex is an individual-based simulation model that follows the fates of each animal in a simulated population from birth to death, with all events happening according to defined probabilities. 


\section{Baseline model input}

Using Vortex (Appendix 1), we developed baseline models incorporating all available information on the Nightingale ReedWarbler. Each model was simulated 1000 times (Owen-Smith 2007) over a time frame of 100 years. We defined extinction as occurring when only one sex remained.

Because little is known about the genetics and effects of inbreeding depression on the Nightingale Reed-Warbler, coupled with the absence of good information on the impact of inbreeding depression, we developed models both with (at the default heterosis model of 6.29 lethal equivalents, $50 \%$ due to recessive lethals) and without inbreeding depression included (Appendix 1). We tested this initial parameterization using equivalency testing in Minitab (version 18). Equivalence testing is a statistical tool used to test whether observations from two groups are similar enough to be biologically analogous. In equivalence testing, the null hypothesis is that the difference between the means is greater than a researcher-defined amount, which is referred to as "interval of tolerable difference." We defined the limits at which we thought model output difference would be equivalent as \pm 0.02 stochastic $\mathrm{r}$ (essentially $\pm 2 \%$ annual growth rate) and \pm 10 individuals remaining at 100 years. We found the growth rate of inbreeding depression models to be nonequivalent to noninbreeding models based upon these defined limits $(p>0.7)$. Although models were equivalent based on population size at 100 years $(\mathrm{p}<0.05)$, this was an artifact of the very small final population sizes $(\leq 4)$, rather than a reflection of equivalency. Given the small population size and current population decline we choose to run all baseline and sensitivity models both with and without inbreeding depression.

We modeled four cohorts or stages: juvenile females, adult females, juvenile males, and adult males. We developed our demographic input parameters from a variety of sources, including original data, previously published information, and discussions with Nightingale Reed-Warbler biologists. We assumed that the effects of environmental variation on reproduction and survival were correlated.

\section{Population dynamics and dispersal}

We modeled populations on Saipan and Alamagan separately, as well as together as a total population. We assumed baseline demographics were the same for each island. For several reasons, we further assumed that if dispersal between islands does exist, it is at levels too low to be meaningful. First, populations on both islands were at best stable to declining (Camp et al. 2009, Marshall et al. 2011) and unlikely to be producing emigrants. Furthermore, genetic testing showed little if any recent gene flow between Saipan and Aguiguan (30 km apart), which is much closer to Saipan than Alamagan ( $250 \mathrm{~km}$; Saitoh et al. 2012). Finally, the closely related Seychelles Warbler (Acrocephalus sechellensis) rarely dispersed even when their current habitat was saturated and there were other suitable islands nearby, despite retaining all the morphological structures for such flight (Komdeur et al. 2004).

\section{Reproduction}

We assumed Nightingale Reed-Warblers are monogamous within the year, but not between years, because in one study males were not seen to associate with more than one female during a breeding season, but females exhibited low mate fidelity between years (Craig 1992). We further assumed that they would breed at one year of age because the congeneric Seychelles Warbler breeds as early as 8-9 months (Komdeur 1991, 1992, 1994a, b) and the congeneric Nihoa Millerbird (Acrocephalus familiaris kingi) is presumed to breed at one year (Conant and Morin 2001). Mosher (2006) found that Nightingale Reed-Warblers nest during two peak seasons (January-March; July-September), and that pairs renested after failure during a given season, but if successful waited to renest until the next season. Thus, we assumed a maximum of two broods per year. However, no data were available on the mean number of successful nests/pair/year. To estimate the distribution of successful broods per year, we used Komdeur and Daan's (2005) distribution of Seychelles Warblers nest attempts/ year, adjusted by Mosher's (2006) Nightingale Reed-Warbler nest success. Although Mosher (2006) witnessed one pair lay four eggs on two occasions, the maximum number of young successfully reared to fledging was three $($ mean $=1.95 \pm 0.65)$, and we assumed this to be the maximum number of progeny per pair per season. Seychelles Warblers successfully breed until nine years old (Komdeur 1996) and Nihoa Millerbirds are presumed to breed until 10 years (Conant and Morin 2001), so we assumed that Nightingale Reed-Warblers can breed until nine years old and live up to 10 years. We also assumed a 1:1 sex ratio at birth.

\section{Density dependence}

Vortex models density dependence in terms of its effect on reproduction as: $\mathrm{P}(\mathrm{N})=\left(\mathrm{P}(0)-\left((\mathrm{P}(0)-\mathrm{P}(\mathrm{K}))^{*}\left((\mathrm{~N} / \mathrm{K})^{\wedge} \mathrm{B}\right)\right)\right)^{*}(\mathrm{~N} /(\mathrm{A}+$ $\mathrm{N})$ ); where $\mathrm{P}(0)$ is the percentage of adult females breeding at low density; $\mathrm{P}(\mathrm{K})$ is the percentage of adult females breeding at carrying capacity; $\mathrm{N}$ is initial population size; $\mathrm{K}$ is carrying capacity; $\mathrm{B}$ is a steepness parameter, which determines the shape of the curve relating the percentage of adult females breeding to population size; and A is the Allee parameter, which accounts for the decrease in the proportion of females breeding at low densities. We assumed that Nightingale Reed-Warblers would be densitydependent, given that it is a territorial bird that defends prime nesting sites and food sources. In the absence of data to the contrary and given that Nightingale Reed-Warblers are currently confined to small remnant habitat areas we assumed the Allee effect was zero. To determine the appropriate steepness parameter, we graphed a series of density-dependent population projection plots using steepness parameters from 0.25 to 16 . A steepness parameter of 8 looked the most reasonable, though 4 and 16 also seemed plausible. To test the influence of the steepness parameter, we ran three versions each of the baseline with and without inbreeding, with steepness values of 4,8 , and 16 , and as with inbreeding, tested for equivalency with Minitab (version 18), within the self-defined limits of \pm 0.02 stochastic $r$ and \pm 10 individuals remaining at 100 years. Because all models showed equivalent results $(\mathrm{p}<0.01)$ we chose to use a steepness value of 8 in our baseline model. We used data from the Seychelles Warbler (Brouwer et al. 2009) to estimate the percent breeding at high and low population densities. At carrying capacity, Seychelles Warblers delay breeding and help breeding birds at the nest, resulting in an average group size of $2.8 \pm 0.1$ birds, which means about $71 \%$ of adult birds are breeding. At low densities, however, no nest helpers are seen, and most territories consist of a pair of breeding birds, with some unpaired floaters. Thus, we assumed $95 \%$ of adult birds breed at low densities. Vortex used the parameters of percent breeding at low density and percent breeding at high density, the Allee parameter and the steepness 
parameter to automatically calculate the percent of adult females breeding. For the environmental variation in percent breeding, we used default values in the absence of other data. Given that the Nightingale Reed-Warbler lives in a somewhat stable, maritime climate, we would not expect large variations from year to year. Finally, we assumed that $100 \%$ of males would be in the breeding pool, though not all find mates.

\section{Mortality}

To determine survival, we developed a series of models in Program MARK (version 8.0) using unpublished data collected on the Nightingale Reed-Warbler by Steven Mosher. Mosher followed 57 marked adult males over 19 months from January 1997 until July 1998, with monthly resighting intervals. We created an encounter history for each bird using the month of initial capture and all resightings in subsequent months. We used the Live Recaptures data type which is a form of Cormack-Jolly-Seber (CJS) model. We compared five models: Phi(.)p(.), which provided mean monthly estimates of survival (Phi) and detection (p) across sex/life stages; Phi(.)p(g), which provided mean monthly estimates of survival (Phi) across sex/life stages and detection ( $p$ ) for each sex/life stage; Phi $(\mathrm{g}) \mathrm{p}($.$) , which provided estimates of$ mean monthly survival for each sex/life stage (g) and the average monthly detection probability (p) across all sex/life stages; Phi(g) $\mathrm{p}(\mathrm{g})$, which provided mean monthly estimates of survival (Phi) and detection (p) for each sex/life stage; and Phi(g)p(g+covar), which provided mean monthly estimates of survival (Phi) and detection ( $p$ ) for each sex/life stage and included an additive effect of typhoons as a covariate of detection. We used the product of monthly survival rates $\left(\mathrm{Phi}^{12}\right)$ to estimate annual survival. Based on AICc, the model Phi $(\mathrm{g}) \mathrm{p}(\mathrm{g}+$ covar $)(\mathrm{AICc}=884.19, \mathrm{k}=6$, Dev. $=872.06)$ was far superior $(\Delta=272.43)$ to the next best model, Phi $(\mathrm{g}) \mathrm{p}(\mathrm{g})(\mathrm{AICc}=1156.93, \mathrm{k}=6$, Dev. $=1144.80)$. The monthly survival probability of adult males was 0.9735 (SE 0.0083 , CI $0.9515,0.9856)$. The mean monthly detection probability of adult males in the absence of typhoons was 0.8325 $(\mathrm{SE}=0.0180, \mathrm{CI} 0.7942,0.8649)$. The annual survival probability of adult males was 0.7243 (CI $0.0700,0.9978$ ). The dataset was insufficient to estimate female and juvenile survival. Given that at least one of $13(\sim 8 \%)$ marked females was depredated on the nest and others have found higher female mortality in passerine species where rat nest predation is an issue (VanderWerf et al. 2011,2014 ), we assumed that female survival would be $10 \%$ lower than males $(62 \%)$. For modeling purposes when better information was unavailable, a juvenile survival rate, which is half of adult survival (generally resulting in $\sim 30 \%$ juvenile survival), has been assumed for migratory passerines (Ricklefs 1973, Donovan et al. 1995). Based on our calculated Nightingale ReedWarbler male survival, this would produce an annual juvenile survival of $36 \%$. However, Seychelles Warbler juveniles exhibit considerably higher survival than $36 \%$, and ostensibly juvenile survival should be slightly higher for a resident, nonmigratory bird species. Thus, we assumed $40 \%$ survival for juveniles. We used these survival estimates in our baseline model because they represent the only estimate of Nightingale Reed-Warbler survival rates. In the absence of better data, as with percent breeding, we felt that in this relatively stable island environment we would not see large annual fluctuations in mortality rates. Thus, we used Vortex's default, relatively modest deviation in mortality rate of $10 \%$ for juvenile mortality and $3 \%$ for adult mortalities.

\section{Catastrophes}

Typhoons and super-typhoons commonly occur in the Marianas Islands. However, the survival and reproductive data used to calculate our parameters (Mosher 2006) were collected during an intense El Nino year, in which four super-typhoons occurred within five months. Since these data represent most of what parameterizes our model, the effect of super-typhoons is already built into our model. To avoid double counting their effect, we have not included them as a separate effect in the model.

\section{Population size and carrying capacity}

In the absence of information to the contrary, we assumed Nightingale Reed-Warbler achieve a stable age distribution. We used the most recent estimates of current population size on Saipan (Camp et al. 2009) and Alamagan (Marshall et al. 2011) in our models. No estimates of carrying capacity exist for either island. However, the amount of suitable habitat is declining (Camp et al. 2009, Marshall et al. 2011) and it is unlikely that $\mathrm{K}$ is much higher than current populations. Thus, to allow for some population growth while reflecting the current decline in habitat, we assumed carrying capacity to be $25 \%$ greater than current populations. In the absence of better information, we assumed fluctuation in $\mathrm{K}$ due to environmental variation to be $\pm 10 \%$.

\section{Software output}

Vortex's standard output provided us with stochastic r, probability of extinction within 25 years, average population size at 25 years, median time to extinction (provided $50 \%$ of simulations went extinct), and mean time to extinction for populations that went extinct within 25 years.

\section{Sensitivity analysis}

We performed sensitivity analysis to understand how data errors or variations affect model outcomes (Akçakaya and SjögrenGulve 2000). We individually varied starting population, carrying capacity, and juvenile, male, female, and combined adult mortalities, number of reproductive attempts per year, and number of young produced per attempt by $\pm 10 \%, \pm 25 \%$, and $\pm 50 \%$, while holding all other parameters to baseline values. We used a standard sensitivity index ( $\mathrm{S}_{x}$; Morris and Doak 2002). Baseline model values were used to compute the standard sensitivity index for each parameter, which was calculated as:

$$
\mathrm{S}_{\mathrm{x}}=\left(\mathrm{x}_{\text {new }}-\mathrm{x}_{\text {baseline }}\right) /\left(\mathrm{P}_{\text {new }}-\mathrm{P}_{\text {baseline }}\right)
$$

where $\mathrm{x}$ is the output value (stochastic $\mathrm{r} / \lambda$ or $\mathrm{N}$ extant) and $\mathrm{P}$ is the parameter of interest.

\section{RESULTS}

Baseline models without inbreeding indicated declines of the Nightingale Reed-Warbler numbers on both Saipan (stochastic $r$ $=-0.0820$ ) and Alamagan (stochastic $r=-0.0849$ ) as well as in the total population (stochastic $r=-0.0815$; Table 1, Fig. 1). Including inbreeding decreased growth rates further (Saipan $=-0.1059$, Alamagan $=-0.1125$, total population $=-0.1091)$. Vortex predicted an $82.5 \%$ chance of total population extinction within 
Table 1. Nightingale Reed-warbler (Acrocephalus hiwae) candidate baseline model results. Note that because of the length of time since population estimation ( 10 years), the times we report here reflect predicted time to extinction since population estimation, rather than from the present.

\begin{tabular}{|c|c|c|c|c|c|c|c|c|c|c|}
\hline Model & Inbreeding & Steepness & Population & $\begin{array}{c}\text { Mean } \\
\text { stochastic } r\end{array}$ & $\begin{array}{c}\mathrm{r} \\
\mathrm{SD}\end{array}$ & $\begin{array}{l}\text { Probability of } \\
\text { extinction (PE) }\end{array}$ & $\begin{array}{c}\text { Population size at } \\
100 \text { years }(\mathrm{N})\end{array}$ & $\begin{array}{l}\mathrm{N} \\
\mathrm{SD}\end{array}$ & $\begin{array}{l}\text { Median time } \\
\text { to extinction }\end{array}$ & $\begin{array}{l}\text { Mean time to } \\
\text { extinction (TE) }\end{array}$ \\
\hline \multirow[t]{3}{*}{ Baseline } & No & 8 & Saipan & -0.082 & 0.167 & 0.858 & 3.17 & 13.1 & 76 & 72.8 \\
\hline & & & Alamagan & -0.0849 & 0.178 & 0.957 & 1.04 & 5.97 & 61 & 61.4 \\
\hline & & & Total & -0.0815 & 0.157 & 0.825 & 4.21 & 14.7 & 80 & 76.9 \\
\hline \multirow[t]{3}{*}{ Baseline } & No & 4 & Saipan & -0.084 & 0.168 & 0.893 & 2.03 & 8.03 & 75 & 72.6 \\
\hline & & & Alamagan & -0.0846 & 0.179 & 0.966 & 0.51 & 3.8 & 62 & 62.3 \\
\hline & & & Total & -0.0833 & 0.157 & 0.868 & 2.55 & 8.91 & 79 & 77 \\
\hline \multirow[t]{3}{*}{ Baseline } & No & 16 & Saipan & -0.0816 & 0.166 & 0.874 & 2.92 & 11 & 76 & 73.5 \\
\hline & & & Alamagan & -0.0837 & 0.179 & 0.95 & 0.95 & 5.33 & 62 & 61.8 \\
\hline & & & Total & -0.0813 & 0.155 & 0.832 & 3.87 & 12.4 & 80 & 77.4 \\
\hline \multirow[t]{3}{*}{ Baseline } & Yes & 8 & Saipan & -0.1059 & 0.161 & 0.999 & 0.02 & 0.36 & 61 & 62 \\
\hline & & & Alamagan & -0.1125 & 0.171 & 1 & 0 & 0 & 49 & 49.1 \\
\hline & & & Total & -0.1091 & 0.152 & 0.999 & 0.02 & 0.36 & 62 & 64 \\
\hline \multirow[t]{3}{*}{ Baseline } & Yes & 4 & Saipan & -0.1066 & 0.163 & 1 & 0.01 & 0.15 & 61 & 62 \\
\hline & & & Alamagan & -0.1114 & 0.171 & 1 & 0 & 0 & 48 & 49.3 \\
\hline & & & Total & -0.1093 & 0.153 & 1 & 0.01 & 0.15 & 62 & 64.1 \\
\hline \multirow[t]{3}{*}{ Baseline } & Yes & 16 & Saipan & -0.1065 & 0.162 & 1 & 0.01 & 0.13 & 61 & 61.9 \\
\hline & & & Alamagan & -0.1128 & 0.171 & 1 & 0 & 0 & 48 & 48.8 \\
\hline & & & Total & -0.1094 & 0.154 & 1 & 0.01 & 0.13 & 62 & 64 \\
\hline
\end{tabular}

100 years without accounting for inbreeding (Saipan $=85.8 \%$, Alamagan $=95.7 \%$ ) and a $99.9 \%$ chance of total population extinction with default inbreeding levels (Saipan $=99.9 \%$, Alamagan $=100 \%$ ) incorporated into the models. Vortex yielded a mean final population size of $4.2 \pm 14.7$ for the total population (Saipan $=3.2 \pm 13.1$, Alamagan $=1.0 \pm 6.0)$ without inbreeding and populations of zero when inbreeding was incorporated. The mean time to extinction for the total population was 76.9 years without inbreeding and 64.0 years with inbreeding included (Saipan $=72.8$ vs. 62.0 years, Alamagan $=61.4$ vs. 49.1 years $)$. The median time to extinction for the total population was 80 years without inbreeding and 62 years with inbreeding included (Saipan $=76$ vs. 61 years, Alamagan $=61$ vs. 49 years $)$. Thus, with inbreeding as a factor, mean time to extinction will be 13 years (median time to extinction $=18$ years) earlier than if inbreeding depression is not a factor. Notably, the baseline population estimates used to calculate these times to extinction are approximately 10 years old at time of publication. Thus, the times we report here reflect predicted time to extinction since population estimation, rather than from the present.

Models showed no difference in relative sensitivity to parameter perturbations whether inbreeding was incorporated into the model or not (Table 2). Growth rate had very little sensitivity to changes in either initial population size or carrying capacity (Table 2). In fact, varying either initial population size or carrying capacity even $\pm 50 \%$ had very little impact. The growth rate was slightly more sensitive to perturbations in fecundity measures and male mortality, though not nearly so sensitive as it was to female and juvenile mortality measures (Table 2). Except at the highest mortalities, growth rate was most sensitive to changes in female mortality (Table 2). As with growth rate, population size at 100 years was relatively insensitive to changes in initial population, carrying capacity, and male mortality (Table 2). Although population size was relatively insensitive to increases in female and juvenile mortality it was quite sensitive to decreases in these parameters (Table 2). Conversely, population size became relatively more sensitive to fecundity measures as these parameters increased (Table 2).

Fig. 1. Average Nightingale Reed-warbler (Acrocephalus hiwae) population size over 100 years for Saipan, Alamagan, and the total population. Note that because of the length of time since population estimation ( $\sim 10$ years), these trajectories commence at population estimation, rather than the present. Population viability was modeled in Vortex, with and without inbreeding.

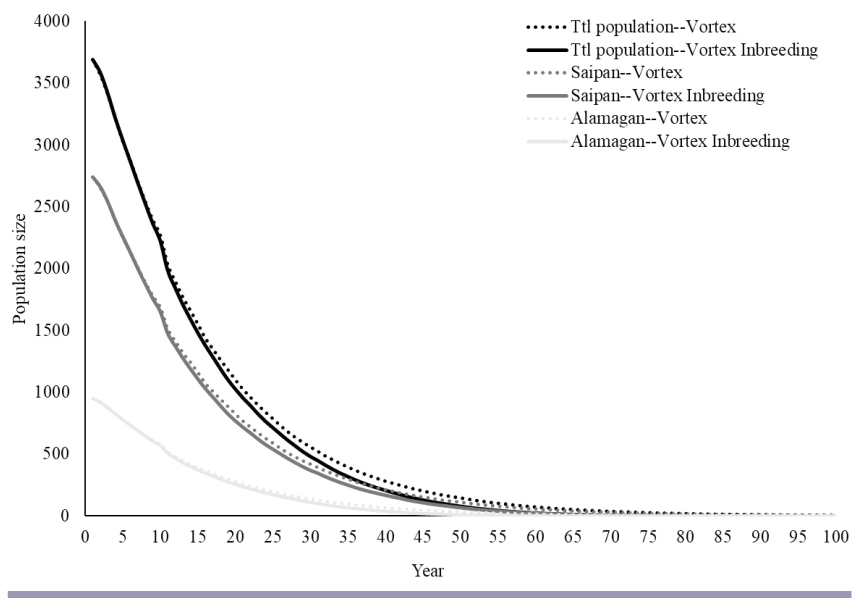

\section{DISCUSSION}

Our models indicate that the Saipan and Alamagan populations of Nightingale Reed-Warbler will be severely decreased, and without management intervention, will likely go extinct within the next 100 years or persist at population sizes that were so low as to signal a strong likelihood of future extinction (Fig. 1). Although these results indicate populations in decline, extinction 
Table 2. Sensitivity analysis of key input parameter influencing Nightingale Reed-Warbler (Acrocephalus hiwae) growth rate and population size at 100 years, without and with inbreeding.

\begin{tabular}{|c|c|c|c|c|c|}
\hline \multirow[t]{2}{*}{ Model } & \multirow[t]{2}{*}{$\begin{array}{l}\text { Magnitude of } \\
\text { variation }\end{array}$} & \multicolumn{2}{|c|}{$\begin{array}{c}\text { Growth rate sensitivity index } \\
(\Delta \mathrm{r} / \Delta \mathrm{x})\end{array}$} & \multicolumn{2}{|c|}{ Pop size at 100 years sensitivity index $(\Delta N / \Delta x)$} \\
\hline & & No Inbreeding & Inbreeding & No Inbreeding & Inbreeding \\
\hline \multirow[t]{6}{*}{ Initial Population } & $50 \%$ & 0.0000 & 0.0000 & -0.0009 & 0.0000 \\
\hline & $25 \%$ & 0.0000 & 0.0000 & -0.0001 & 0.0000 \\
\hline & $10 \%$ & 0.0000 & 0.0000 & -0.0025 & 0.0000 \\
\hline & $-10 \%$ & 0.0000 & 0.0000 & 0.0035 & 0.0000 \\
\hline & $-25 \%$ & 0.0000 & 0.0000 & 0.0015 & 0.0000 \\
\hline & $-50 \%$ & 0.0000 & 0.0000 & 0.0013 & 0.0000 \\
\hline \multirow[t]{6}{*}{ Carrying Capacity } & $50 \%$ & 0.0000 & 0.0000 & -0.0002 & 0.0000 \\
\hline & $25 \%$ & 0.0000 & 0.0000 & 0.0000 & 0.0000 \\
\hline & $10 \%$ & 0.0000 & 0.0000 & -0.0010 & 0.0000 \\
\hline & $-10 \%$ & 0.0000 & 0.0000 & 0.0018 & 0.0000 \\
\hline & $-25 \%$ & 0.0000 & 0.0000 & 0.0018 & 0.0000 \\
\hline & $-50 \%$ & 0.0000 & 0.0000 & 0.0013 & 0.0000 \\
\hline \multirow[t]{6}{*}{ Juvenile Mortality } & $50 \%$ & -1.0360 & -0.9640 & -14.0333 & -0.0667 \\
\hline & $25 \%$ & -0.9147 & -0.8220 & -28.0667 & -0.1333 \\
\hline & $10 \%$ & -0.9017 & -0.7950 & -70.1667 & -0.3333 \\
\hline & $-10 \%$ & -0.9467 & -0.9417 & -8609.8333 & -1837.6667 \\
\hline & $-25 \%$ & -0.5927 & -0.7553 & -23912.0000 & -20800.7333 \\
\hline & $-50 \%$ & -0.3903 & -0.4700 & -14056.7000 & -13702.2333 \\
\hline \multirow{6}{*}{ Female Mortality } & $50 \%$ & -0.9179 & -0.8411 & -22.1579 & -0.1053 \\
\hline & $25 \%$ & -0.9811 & -0.9084 & -44.3158 & -0.2105 \\
\hline & $10 \%$ & -1.0211 & -0.9526 & -110.2632 & -0.5263 \\
\hline & $-10 \%$ & -1.1421 & -1.0868 & -5040.7895 & -732.8947 \\
\hline & $-25 \%$ & -0.8400 & -1.0653 & -26047.6842 & -17834.1053 \\
\hline & $-50 \%$ & -0.5958 & -0.7258 & -21774.4737 & -21316.7368 \\
\hline \multirow[t]{6}{*}{ Male Mortality } & $50 \%$ & -0.0871 & -0.0786 & -22.7143 & -0.1429 \\
\hline & $25 \%$ & -0.0929 & -0.0729 & -24.5714 & 0.1429 \\
\hline & $10 \%$ & -0.0964 & -0.0821 & -41.4286 & 0.0000 \\
\hline & $-10 \%$ & -0.0536 & -0.0929 & -0.7143 & -1.4286 \\
\hline & $-25 \%$ & -0.0400 & -0.0957 & 2.4286 & -0.7143 \\
\hline & $-50 \%$ & -0.0443 & -0.0807 & -3.1429 & -0.2143 \\
\hline \multirow[t]{6}{*}{ Adult Mortality } & $50 \%$ & -1.2552 & -1.1836 & -25.5152 & -0.1212 \\
\hline & $25 \%$ & -1.2618 & -1.1939 & -51.0303 & -0.2424 \\
\hline & $10 \%$ & -1.2485 & -1.1606 & -126.9697 & -0.6061 \\
\hline & $-10 \%$ & -1.3364 & -1.2818 & -5778.1818 & -1021.8182 \\
\hline & $-25 \%$ & -0.9782 & -1.2303 & -31215.7576 & -20539.0303 \\
\hline & $-50 \%$ & -0.6848 & -0.8364 & -25227.7576 & -24970.3030 \\
\hline \multirow[t]{6}{*}{ \#Attempts/Year } & $50 \%$ & 0.2238 & 0.2785 & 8377.5289 & 7842.4711 \\
\hline & $25 \%$ & 0.3473 & 0.4028 & 8582.1709 & 3580.9700 \\
\hline & $10 \%$ & 0.4353 & 0.3995 & 1481.5242 & 168.8222 \\
\hline & $-10 \%$ & 0.2702 & 0.2460 & 46.8822 & 0.2309 \\
\hline & $-25 \%$ & 0.3081 & 0.2808 & 19.4457 & 0.0924 \\
\hline & $-50 \%$ & 0.3236 & 0.2954 & 9.7229 & 0.0462 \\
\hline \multirow[t]{6}{*}{ \#Offspring/Attempt } & $50 \%$ & 0.1040 & 0.1292 & 3841.7231 & 3712.4308 \\
\hline & $25 \%$ & 0.1594 & 0.1965 & 4395.0769 & 2560.7179 \\
\hline & $10 \%$ & 0.1969 & 0.1754 & 715.6410 & 74.2051 \\
\hline & $-10 \%$ & 0.1795 & 0.1585 & 21.5385 & 0.1026 \\
\hline & $-25 \%$ & 0.1848 & 0.1670 & 8.6359 & 0.0410 \\
\hline & $-50 \%$ & 0.1909 & 0.1720 & 4.3179 & 0.0205 \\
\hline
\end{tabular}

is not inevitable because there is still time left to conduct management activities that have potential to reverse these trends.

Sensitivity results indicate that parameters such as initial population, carrying capacity, and male mortality/survival have relatively little influence on the Nightingale Reed-Warbler total population model relative to other parameters (Table 2). On the other hand, sensitivity analyses suggested that we need to gain further understanding of female and juvenile survival and, to a lesser degree, annual fecundity measures, because they exhibit strong influence on the Nightingale Reed-Warbler's population dynamics. Unfortunately, no data on female and juvenile survival currently exist, and thus we estimated these parameters from male survival and patterns of survival in congeners and other species. Although several parameters were insensitive to changes in terms of model output, it is important to note that they are still important to measure accurately. For instance, although changes in initial population size did not strongly affect model outputs, 
such as growth rate and final population size, it will affect time to extinction, and as a result, the time left to try to take management actions to prevent extinction. All else being equal, the Alamagan population, with its smaller initial population size, will likely go extinct quicker than the larger Saipan population, simply because of its smaller initial size. Similarly, while incorporating effects of inbreeding into the models did not significantly change model outcome, it did speed up the population decline. Thus, having a better understanding of whether inbreeding affects Nightingale Reed-Warbler populations, and if so, how it does so, will refine model predictions. In some cases, life history and demographic information for a species is simply absent, and while related species can provide important information for PVA models, if they exist in entirely different environments, or are not closely related, their value may be limited. Several specific demographic measures used in the PVA were developed based on the best available data. However, as additional species-specific data become available, it will likely lead to better parameter estimation, and eventually, more accurate model results.

Although all models suggest a species in decline, there are several caveats that may have strong relevance for future modeling and management efforts. First, we assumed that the populations on Alamagan and Saipan operate in a similar manner and that they have the same demographic attributes. Although both populations occur in the same archipelago, they do have unique environmental settings and thus may differ in terms of population dynamics. In fact, the two islands have somewhat different historic population trends with Alamagan showing an essentially steady, though perhaps slowly declining, population of Nightingale Reed-Warblers (Marshall et al. 2011) compared to Saipan which has been declining more quickly (Camp et al. 2009). One limitation of our analysis is that all previous research has been on Saipan reed-warblers, such that both the Alamagan and Saipan populations have been modeled with Saipan demographics. As a result, the models of Saipan's population may be more robust than Alamagan's. Because Alamagan's reed-warbler population is declining more slowly, it is conceivable that its population outlook may be more optimistic than what we have modeled. Second, nearly all the data used to parameterize the models were over 20 years old. Although many bird species exhibit some consistencies in life history attributes, e.g., average clutch size, many vary based upon environmental conditions, e.g., mortality and fecundity. Given that the populations face the threats of nonnative predators, habitat degradation due to feral species on Alamagan, and habitat loss due to development on Saipan, it is quite likely that the species demographics have changed over time. Third, as previously noted, the parameters to which PVA models are sensitive may change as the model changes. It is important to remember that all population and management inferences drawn from the current models assumed that parameter estimates were reasonable approximations of the Nightingale Reed-Warbler's true demography and life history. As new data are collected, and the model is refined and developed, new conclusions may be drawn, and management decisions updated. For instance, our current model was relatively insensitive to changes in carrying capacity, which would be expected if the populations are currently declining for reasons other than declining carrying capacity, such that carrying capacity has little effect on population dynamics.
However, if recovery efforts succeed and the populations increase, carrying capacity may become quite important, and would need to be better understood to effectively model the populations. The same may be said of the true effects of density dependence on reproductive efforts and other parameters as well.

\section{Research and management implications}

As evidenced by the PVA results, the Nightingale Reed-Warbler is a species under severe threat. All models suggested that the species will rapidly decline and may go extinct within the next 100 years without management intervention. Based upon the underlying data used in the models and the model output, we recommend the following research and management items. First, given the models' sensitivity to survival and the fact that these estimates are the least robust, we recommend effort be placed on collecting additional survival data for all life stages, but particularly females and juveniles. If current survival estimates prove to be reasonable, we recommend management actions that would increase survival of juveniles and females. Potential management activities could include reducing non-native predators (particularly rats), increasing Nightingale ReedWarbler food resources, and restoring high-quality native habitat.

Second, given the length of time since reproductive data have been collected and the moderate sensitivity of models to these parameters, we recommend collecting new data on reproduction and other demographic factors. Because environmental conditions may have changed since the data were collected, it is important to evaluate if reproduction has decreased. Furthermore, because data collected during 1997-1998 were during a time of atypical weather patterns, including four supertyphoons, it is difficult to discern what reproduction and other demographic factors may look like during periods of more stable weather patterns. Ideally, data would be collected over a longer interval to allow for evaluation of demographic factors during periods of stable weather and periods of typhoons. Such data could allow for evaluation of reproduction under different storm and typhoon frequencies and severities. Given the potential effects of global change on regional climatic patterns and El Nino and typhoon frequencies, understanding such variability is of considerable importance.

Third, given that Saipan and Alamagan show different population trends, we recommend collecting new data on species demography and life history attributes from both islands to determine if the two populations behave similarly. If they do, it may allow for a simpler management approach. However, if the populations are displaying different dynamics, then management may need to be individualized by island. For example, if Alamagan's population is stable, understanding the differences between its population dynamics and Saipan's may aid in understanding how to better manage reed-warblers on Saipan. Although additional data would provide much needed answers to Nightingale ReedWarbler population dynamics, it is extremely important to concurrently implement management actions in the near term. It is critical that management of other invasive species commence, including eliminating feral ungulates, controlling ivy gourd, and controlling predators, with the aim of restoring habitat, including food resources. Beyond management within the existing habitat, it will likely be necessary to set aside protected areas, in addition 
Avian Conservation and Ecology 13(2): 13

to the existing Saipan Upland Mitigation Bank, the Nightingale Reed-Warbler Conservation Area, and other conservation areas on Saipan for enough quality habitat to exist. One approach being considered to increase habitat and reduce extinction risk is translocating reed-warblers from Saipan and/or Alamagan to at least two islands - Pagan and Aguiguan, because closely related reed-warblers once occurred on both islands - to create new populations (MAC Working Group 2013). Engaging in management in the near-term future, before the populations' exhibit further large reductions, is critical.

Responses to this article can be read online at:

http://www.ace-eco.org/issues/responses.php/1289

\section{Acknowledgments:}

We wish to thank Barry Grand for assistance with developing survival estimates and Steven Mosher for providing original data. In addition, we would like to thank Joseph J. Nocera, Erik Blomberg, and an anonymous reviewer for their helpful comments on our draft manuscript. Funding for this work was provided by the U.S. Fish and Wildlife Service's Cooperative Endangered Species Conservation Fund awarded to the CNMI Department of Lands and Natural Resources, in collaboration with the University of Hawai'i.

\section{LITERATURE CITED}

Akçakaya, H. R., and P. Sjögren-Gulve. 2000. Population viability analysis in conservation planning: an overview. Ecological Bulletins 48:9-21.

Amidon, F., R. J. Camp, A. P. Marshall, T. K. Pratt, L. Williams, P. Radley, and J. B. Cruz. 2014. Terrestrial bird population trends on Aguiguan (Goat Island), Mariana Islands. Bird Conservation International 24:505-517. http://dx.doi.org/10.1017/S0959270914000021

Beissinger, S. R., and M. I. Westphal. 1998. On the use of demographic models of population viability in endangered species management. Journal of Wildlife Management 62:821-841. http://dx.doi.org/10.2307/3802534

BirdLife International. 2016. Saipan Reed-warbler: Acrocephalus hiwae. The IUCN Red List of Threatened Species 2016:e. T103780118A104318648. http://dx.doi.org/10.2305/IUCN.UK.2016-3. RLTS.T103780118A104318648.en

Brook, B. W., J. J. O'Grady, A. P. Chapman, M. A. Burgman, H. R. Akçakaya, and R. Frankham. 2000. Predictive accuracy of population viability analysis in conservation biology. Nature 404:385-387. http://dx.doi.org/10.1038/35006050

Brouwer, L., J. M. Tinbergen, C. Both, R. Bristol, D. S. Richardson, and J. Komdeur. 2009. Experimental evidence for density-dependent reproduction in a cooperatively breeding passerine. Ecology 90:729-741. http://dx.doi.org/10.1890/07-1437.1

Camp, R. J., T. K. Pratt, A. P. Marshall, F. Amidon, and L. L. Williams. 2009. Recent status and trends of the land bird avifauna on Saipan, Mariana Islands, with emphasis on the endangered Nightingale Reed-warbler, Acrocephalus luscinia. Bird Conservation International 19:323-337. http://dx.doi.org/10.1017/S0959270909008417
Conant, S., and M. Morin. 2001. Why isn't the Nihoa Millerbird extinct? Studies in Avian Biology 22:338-346.

Craig, R. J. 1992. Territoriality, habitat use and ecological distinctiveness of an endangered Pacific island reed-warbler. Journal of Field Ornithology 63:436-444.

Cross, P. C., and S. R. Beissinger. 2001. Using logistic regression to analyze the sensitivity of PVA models: a comparison of methods based on African wild dog models. Conservation Biology 15:1335-1346. http://dx.doi.org/10.1111/j.1523-1739.2001.00031. $\mathrm{x}$

Cruz, J., L. Arriola, N. Johnson, and G. Beauprez. 2000a. Wildlife and vegetation surveys Alamagan 2000. Technical Report \#4. Commonwealth of the Northern Mariana Islands, Division of Fish \& Wildlife, Saipan, Mariana Islands. [online] URL: http:// www.dfw.gov.mp/Wildlife/Wild_Downloads/Tech_4_Alamagan_2000. pdf

Cruz, J., L. Arriola, N. Johnson, and G. Beauprez. 2000b. Wildlife and vegetation surveys Aguiguan 2000. Technical Report \#2. Commonwealth of the Northern Mariana Islands, Division of Fish \& Wildlife, Saipan, Mariana Islands. [online] URL: http:// www.cnmi-dfw.com/docs/Tech $\% 20$ Rpt $\% 202 \% 20-\% 20$ Aguiguan $\%$ 202000.pdf

Deleon Guerrero, V. 2015. CNMI's forest action plan update 2015 2020. Commonwealth of the Northern Mariana Islands Department of Lands and Natural Resources Division of Agriculture, Saipan, Mariana Islands.

Donovan, T. M., F. R. Thompson III, J. Faaborg, and J. R. Probst. 1995. Reproductive success of migratory birds in habitat sources and sinks. Conservation Biology 9:1380-1395. http://dx.doi. org/10.1046/j.1523-1739.1995.09061380.x

Ellner, S. P., and J. Fieberg. 2003. Using PVA for management despite uncertainty: effects of habitat, hatcheries, and harvest on salmon. Ecology 84:1359-1369. http://dx.doi.org/10.1890/0012-9658 (2003)084[1359:UPFMDU]2.0.CO;2

Engbring, J., F. L. Ramsey, and V. J. Wildman. 1986. Micronesian forest bird survey, 1982: Saipan, Tinian, Aguijan, and Rota. U.S. Fish \& Wildlife Service Report.

Esselstyn, J., J. B. Cruz, L. L. Williams, and N. Hawley. 2003. Wildlife and vegetation surveys: Aguiguan 2002. Technical Report \#9. Commonwealth of the Northern Mariana Islands, Division of Fish \& Wildlife, Saipan, Mariana Islands.

Global Invasive Species Database. 2017. Species profile: Coccinia grandis. International Union for Conservation of Nature Species Survival Commission Invasive Species Specialist Group. [online] URL: http://www.iucngisd.org/gisd/species.php?sc =348

Komdeur, J. 1991. Cooperative breeding in the Seychelles warbler. Dissertation. University of Cambridge, Cambridge, UK.

Komdeur, J. 1992. Importance of habitat saturation and territory quality for evolution of cooperative breeding in the Seychelles warbler. Nature 358:493-495. http://dx.doi.org/10.1038/358493a0

Komdeur, J. 1994a. Conserving the Seychelles warbler Acrocephalus sechellensis by translocation from Cousin Island to the Islands of Aride and Cousine. Biological Conservation 67:143-152. http://dx.doi.org/10.1016/0006-3207(94)90360-3 
Avian Conservation and Ecology 13(2): 13

Komdeur, J. 1994b. The effect of kinship on helping in the cooperative breeding Seychelles Warbler (Acrocephalus sechellensis). Proceedings of the Royal Society of London B: Biological Sciences 256:47-52. http://dx.doi.org/10.1098/rspb.1994.0047

Komdeur, J. 1996. Influence of helping and breeding experience on reproductive performance in the Seychelles warbler: a translocation experiment. Behavioral Ecology 7:326-333. http:// dx.doi.org/10.1093/beheco/7.3.326

Komdeur, J., and S. Daan. 2005. Breeding in the monsoon: semiannual reproduction in the Seychelles Warbler (Acrocephalus sechellensis). Journal of Ornithology 146:305-313. http://dx.doi. org/10.1007/s10336-005-0008-6

Komdeur, J., T. Piersma, K. Kraaijeveld, F. Kraaijeveld-Smit, and D. S. Richardson. 2004. Why Seychelles Warblers fail to recolonize nearby islands: unwilling or unable to fly there? Ibis 146:298-302. http://dx.doi.org/10.1046/j.1474-919X.2004.00255. $\mathrm{x}$

Lacy, R. C., and J. P. Pollak. 2014. Vortex: a stochastic simulation of the extinction process. Version 10.0. Chicago Zoological Society, Brookfield, Illinois, USA.

Liske-Clark, J. 2015. Wildlife action plan for the Commonwealth of the Northern Mariana Islands, 2015-2025. CNMI Department of Lands and Natural Resources-Division of Fish and Wildlife, Saipan, Northern Mariana Islands.

Marianas Avifauna Conservation (MAC) Working Group. 2013. Marianas Avifauna Conservation (MAC) plan: long-term conservation plan for the native forest birds of the Northern Mariana Islands. CNMI Division of Fish and Wildlife, Saipan, and U.S. Fish and Wildlife Service, Honolulu, Hawaii, USA.

Marshall, A., F. Amidon, and P. Radley. 2011. Nightingale ReedWarbler surveys on Alamagan. Appendix 1. Status of the Micronesian Megapode in the Commonwealth of the Northern Mariana Islands. U.S. Fish and Wildlife Service report to the U. S. Navy. Honolulu, Hawaii, USA.

Morris, W. F., and D. F. Doak. 2002. Quantitative conservation biology: theory and practice of population viability analysis. Sinauer Associates, Sunderland, Massachusetts, USA.

Mosher, S. M. 2006. Ecology of the endangered Nightingale ReedWarbler (Acrocephalus luscinia) on Saipan, Micronesia. Thesis, University of Idaho, Moscow, Idaho, USA.

Mosher, S. M., and S. G. Fancy. 2002. Description of nests, eggs, and nestlings of the endangered Nightingale Reed-Warbler on Saipan, Micronesia. Wilson Bulletin 114:1-10. http://dx.doi. org/10.1676/0043-5643(2002)114[0001:DONEAN]2.0.CO;2

Owen-Smith, N. 2007. Introduction to modeling in wildlife and resource conservation. Blackwell, Malden, Massachusetts, USA.

Reed, J. M., L. S. Mills, J. B. Dunning Jr, E. S. Menges, K. S. Mckelvey, R. Frye, S. R. Beissinger, M.-C. Anstett, and P. Miller.
2002. Emerging issues in population viability analysis. Conservation Biology 16:7-19. http://dx.doi.org/10.1046/ j.1523-1739.2002.99419.x

Reichel, J. D., G. J. Wiles, and P. O. Glass. 1992. Island extinctions: the case of the endangered Nightingale Reed-Warbler. Wilson Bulletin 104:44-54.

Ricklefs, R. E. 1973. Fecundity, mortality, and avian demography. Pages 366-435 in D. S. Farner, editor. Breeding biology of birds. National Academy of Science, Washington, D.C., USA.

Rodda, G. H., and J. A. Savidge. 2007. Biology and impacts of Pacific island invasive species. 2. Bioga irregularis, the Brown Tree Snake (Reptilia: Columbridae). Pacific Science 61:307-324. http:// dx.doi.org/10.2984/1534-6188(2007)61[307:BAIOPI]2.0.CO;2

Saitoh, T., A. Cibois, S. Kobayashi, E. Pasquet, and J.-C. Thibault. 2012. The complex systematics of the Acrocephalus of the Mariana Islands, western Pacific. Emu 112:343-349. http://dx.doi. org/10.1071/MU12012

U.S. Fish and Wildlife Service (USFWS). 1970. Conservation of endangered species and other fish and wildlife. Federal Regulation 35:18319-18322.

U.S. Fish and Wildlife Service (USFWS). 1998. Recovery plan for the Nightingale Reed-warbler (Acrocephalus luscinia). U.S. Fish and Wildlife Service, Portland, Oregon, USA.

VanderWerf, E. A., L. H. Crampton, J. S. Diegmann, C. T. Atkinson, and D. L. Leonard. 2014. Survival estimates of wild and captive-released Puaiohi, an endangered Hawaiian thrush. Condor 116:609-618. http://dx.doi.org/10.1650/CONDOR-14-18.1

VanderWerf, E. A., S. M. Mosher, M. D. Burt, P. E. Taylor, and D. Sailer. 2011. Variable efficacy of rat control in conserving O'ahu 'Elepaio populations. Pages 124-130 in C. R. Veitch, M. N. Clout, and D. R. Towns, editors. Island invasives: eradication and management. International Union for Conservation of Nature, Gland, Switzerland.
Editor-in-Chief: Keith A.Hobson Subject Editor: Erik Blomberg
Sponsored by the Society of Canadian Ornithologists and Bird Studies Canada Parrainée par la Société des ornithologistes du Canada et Etudes d'oiseaux Canada

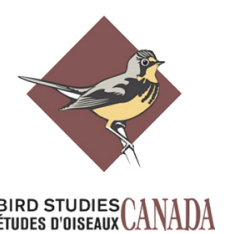


Appendix 1. Parameter inputs for the baseline Nightingale Reed-Warbler (Acrocephalus hiwae) population as modeled in Vortex.

Parameter/variable

Estimate

Scenario Settings

\# iterations

\# years

Duration of year (days)

365

Extinction definition

\# of populations

Only 1 sex remains

Species Description

Inbreeding Depression

Lethal Equivalent

Default $=6.29$

$\%$ due to Recessive Lethals

Default $=50 \%$

EV Concordance of Reproduction and

Survival?

yes, 0.5 between populations

Dispersal

Reproductive System

Reproductive System

Age of $1^{\text {st }}$ Offspring Females

monogamous within year

Age of $1^{\text {st }}$ Offspring Males

1 year

Max Age of Reproduction

1 year

Max Lifespan

9 years

Max \# Broods/Year

10 years

Max \# Progeny/Brood

Sex Ratio at birth in \% Males

Density Dependent Reproduction

$\%$ Breeding at Low Density

Yes

$\%$ Breeding at $\mathrm{K}$

$95 \%$

Allee Parameter

$71 \%$

Steepness Parameter

8

Reproductive Rates

$\%$ Adult Females Breeding

Calculated from density dependence information

$\mathrm{EV}(\mathrm{SD})$ in \% Breeding

Distribution of Broods each Year

\# Offspring/Female/brood (mean \pm SD)

$0-32.47 \% ; 1-48.41 \% ; 2-19.1 \%$

mean $=0.866 \pm 0.710$

Mortality Rates

$1.95 \pm 0.65$

Female Mortality as \% 
SD in Mort from 0 to 1

Annual Mort after Age 1

SD in Mort after Age 1

Male Mortality as \%

Mort from 0 to 1 $\mathrm{SD}$ in Mort from 0 to 1 Annual Mort after Age 1

SD in Mort after Age 1
$10 \%$

$38 \%$

$3 \%$

$60 \%$

$10 \%$

$28 \%$

$3 \%$

Did not incorporate as an additional parameter as survival and reproduction are calculated from data collected during a period with four supertyphoons

Mate Monopolization

Initial Population Size

Stable Age Distribution?

Yes

Initial Population Size

Carrying Capacity

$\mathrm{K}$

$\mathrm{SD}$ in $\mathrm{K}$ due to $\mathrm{EV}$

Alamagan_946; Saipan—2742

Saipan-3430; Alamagan-1180

Saipan-343; Alamagan-118 